\title{
INFLUENCE OF LUNG VOLUME, FLUID AND CAPILLARY RECRUITMENT DURING POSITIONAL CHANGES AND EXERCISE ON THORACIC IMPEDANCE IN HEART FAILURE
}

\author{
Chul-Ho Kim, Ph.D ${ }^{1}$, Matthew A. Fuglestad, B.S. ${ }^{1}$, Malie L. Ceridon Richert, Ph.D. ${ }^{1}$, Win K. \\ Shen, M.D. ${ }^{2}$, and Bruce D. Johnson, Ph.D. ${ }^{1}$ \\ ${ }^{1}$ Division of Cardiovascular Diseases, Mayo Clinic, Rochester, MN \\ ${ }^{2}$ Division of Cardiovascular Diseases, Mayo Clinic, Scottsdale, AZ
}

\begin{abstract}
It is unclear how dynamic changes in pulmonary-capillary blood volume $(\mathrm{Vc})$, alveolar lung volume (derived from end-inspiratory lung volume, EILV) and interstitial fluid (ratio of alveolar capillary membrane conductance and pulmonary capillary blood volume, $\mathrm{Dm} / \mathrm{Vc}$ ) influence lung impedance $\left(\mathrm{Z}_{\mathrm{T}}\right)$. The purpose of this study was to investigate if positional change and exercise result in increased EILV, Vc and/or lung interstitial fluid, and if $Z_{\mathrm{T}}$ tracks these variables.
\end{abstract}

Methods-12 heart failure (HF) patients underwent measurements $\left(\mathrm{Z}_{\mathrm{T}}, \mathrm{EILV}, \mathrm{Vc} / \mathrm{Dm}\right)$ at rest in the upright and supine positions, during exercise and into recovery. Inspiratory capacity was obtained to provide consistent measures of EILV while assessing $\mathrm{Z}_{\mathrm{T}}$.

Results $-\mathrm{Z}_{\mathrm{T}}$ increased with lung volume during slow vital capacity maneuvers $(\mathrm{p}<0.05)$. Positional change (upright $\rightarrow$ supine) resulted in an increased $Z_{T}(p<0.01)$, while $V_{c}$ increased and EILV and Dm/Vc decreased ( $\mathrm{p}<0.05)$. Moreover, during exercise $\mathrm{Vc}$ and EILV increased and $\mathrm{Dm} / \mathrm{Vc}$ decreased $(\mathrm{p}<0.05)$, whereas, $\mathrm{Z}_{\mathrm{T}}$ did not change significantly $(\mathrm{p}>0.05)$.

Conclusion-Impedance appears sensitive to changes in lung volume and body position which appear to generally overwhelm small acute changes in lung fluid when assed dynamically at rest or during exercise.

\section{Keywords}

Heart failure; lung impedance; fluid accumulation

(C) 2014 Elsevier B.V. All rights reserved.

Corresponding Author: Chul-Ho Kim, Ph.D., Research Fellow, Division of Cardiovascular Disease, Department of Internal Medicine, Mayo Clinic, Rochester, MN, 55905, Tel: (507) 255-5859, Kim.chulho@ mayo.edu.

\section{Disclosures}

None of authors have financial interests in the research project.

Publisher's Disclaimer: This is a PDF file of an unedited manuscript that has been accepted for publication. As a service to our customers we are providing this early version of the manuscript. The manuscript will undergo copyediting, typesetting, and review of the resulting proof before it is published in its final citable form. Please note that during the production process errors may be discovered which could affect the content, and all legal disclaimers that apply to the journal pertain. 


\section{INTRODUCTION}

According to the American Heart Association, in 2012, 5.7 million people in the United

States suffered from heart failure (HF) (Roger et al., 2012). Heart failure is a leading cause of hospitalization in individuals over the age of 65 with most patients presenting with dyspnea from pulmonary congestion and poor perfusion (Lewin et al., 2005; Lepage, 2008). Despite advanced treatments, many HF patients are re-admitted to hospitals, with a rate that approaches $25 \%$ within the first thirty days of original admission (Cleland et al., 2003; Ross et al., 2009). Early detection of intrathoracic fluid accumulation is important to predict or prevent decompensation and rehospitalization (Vollmann et al., 2007).

Currently, the techniques for tracking decompensation or general fluid accumulation in HF patients includes daily measures of weight or other more complicated measures such as chest X-ray or CT scans of the lungs, however, it is expensive and/or the diagnostic sensitivity of these techniques is not high (Mahdyoon et al., 1989; Becher et al., 2010; Gupta et al., 2012). In addition, B-type natriuretic peptide (BNP) level, which often increases when HF symptoms are exacerbated, is still in question (Lewin et al., 2005; Becher et al., 2010). As fluid accumulation is one of the major predictors of decompensative events associated with HF, it is very important to develop more sensitive and cost-effective techniques.

Impedance, the measure of resistance to the flow of current, has been considered a novel technique for early detection of fluid retention and decompensation (Yu et al., 2005; Andriulli 2007; Yupenburg et al., 2007; Wang, 2007; Becher et al., 2010). Recently Medtronic Inc. (Minneapolis, MN) released the Optivol ${ }^{\mathrm{TM}}$ software, as a unique way of providing preemptive data on disease status by measuring intrathoracic impedance changes from their implantable cardioverter defibrillator (ICD) or cardiac resynchronization therapy device (CRT-D). This technique is based on the fact that fluid is a better conductor of electricity than the lung or other tissues. However, impedance simply measures resistance between two points and whether or not this reflects actual changes in extravascular lung water remains speculative. In fact, pulmonary congestion itself remains poorly defined and can include changes in extravascular lung water, engorgement of the larger pulmonary vessels, the compliant pulmonary capillaries, the bronchial circulation or changes in all of these vascular and fluid beds (Olson et al., 2007; Ceridon et al., 2009). In addition, changes in lung volume can also significantly impact the impedance measure. Thus, changes detected or quantified with Optivol ${ }^{\mathrm{TM}}$ could include changes in intrathoracic blood volume, extravascular lung water and/or changes in operational lung volume (actual inflation volume of the lungs).

A common problem in HF is orthopnea, which may be caused by a centralization of blood volume or changes in lung fluid volume. In addition, acute exercise has been suggested to cause increases in extravascular lung water through a rise in cardiac output, although this also should expand pulmonary capillary blood volume (Olson et al., 2006). More recently we have adapted a technique in our laboratory that involves the inhalation of small amounts of carbon monoxide (CO) and nitric oxide (NO) simultaneously (Snyder et al., 2008; Ceridon et al., 2010). The resistance to the uptake of CO gas is dependent on the alveolarcapillary membrane (Dm) and subsequently the reaction rates with hgb, which is influenced 
by the capillary blood volume $(\mathrm{Vc})$. Nitric oxide has such a high affinity for hemoglobin (hgb) ( 8000 times faster than CO) and therefore is essentially limited only by the resistance of the alveolar-capillary membrane and thus becomes a measure of alveolar-capillary conductance and interstitial lung fluid changes (Ceridon et al., 2010).

The purpose of the present study was to determine which physiological measure/s (air, blood, water) would contribute the most to changes in intrathoracic impedance during acute interventions (positional changes and exercise) known to cause significant changes in lung volume, blood flow and volume in the lungs as well as the potential to cause shifts in intra to extravascular lung water. Blood and fluid would be inversely related to impedance, while air would be directly related to impedance. It was hypothesized that, a body position change from upright to supine as well as exercise would increase pulmonary capillary blood volume $(\mathrm{Vc})$, extravascular lung water (reduced Dm) and differentially influence lung air volume (fall in operational lung volume with supine position but increase average lung volume with exercise) and that measure of intrathoracic impedance would primarily track the changes in pulmonary capillary blood volume $(\mathrm{Vc})$ and alveolar-capillary membrane conductance (Dm).

\section{METHODS}

\subsection{Subjects}

Twelve HF patients (eight males and four females, age $=63 \pm 8 \mathrm{yr}$, left ventricle ejection fraction $41 \pm 14 \%$, wt $84 \pm 17 \mathrm{~kg}$ ) took part in the present study. Subject characteristics are illustrated in table 1 . The subjects had left ventricular dysfunction and a previously implanted biventricular implantable cardioverter defibrillator; Medtronic InSync II Marquis family CRT-D (Model 7289), Medtronic InSync Maximo CRT-D (Model 7303 or 7304) and Medtronic InSync Sentry family CRT-D (Model 7297, 7298 and 7299). The exclusion criteria included a history of lung disease, anemia, exercise-induced ischemia, end-stage renal disease, pregnancy, body mass index (BMI) $>40$ or New York heart association (NYHA) class IV. Patients were kept on stable optimized medications (i.e. beta-blockers, angiotensin-converting enzyme inhibitors and/or aspirin) and did not have orthopedic limitations to exercise. Prior to participation, the protocol was reviewed with each patient and all subjects completed informed consent. The study was approved by Mayo Clinic Institutional Review Board.

\subsection{Fluid status monitoring and assessment of fluid index}

Intrathoracic impedance $\left(\mathrm{Z}_{\mathrm{T}}\right)$ was obtained via an insertion of measurement software provided by Medtronic Inc (Minneapolis, MN) into the respective existing CRT device. It measures changes in impedance from the right ventricular lead to an implanted pulse generator. A number of studies have suggested that impedance data are well correlated with the risk of decompensatory events in HF patients (Yu et al., 2005; Abraham et al., 2009; Small et al., 2009). Continuous telemetry of impedance data were assessed beat-to-beat using the DR190 Holter recorder throughout the entire testing protocol.

Pulmonary capillary blood volume (Vc) and alveolar-capillary membrane conductance (Dm) were calculated to assess changes in pulmonary blood volume and lung fluid status. 
Previously we have demonstrated that this technique is sensitive to changes in blood volume and extravascular lung water assessed with CT (Snyder et al., 2006). A decrease in the $\mathrm{Dm} / \mathrm{Vc}$ ratio is associated with accumulating extravascular lung water. To determine $\mathrm{Dm}$, $\mathrm{Vc}$ and $\mathrm{Dm} / \mathrm{Vc}$, simultaneous assessment of the diffusing capacity of the lungs for carbon dioxide (DLCO) and nitric oxide (DLNO) were conducted. This has been validated previously in our laboratory relative to the traditional method of measuring $\mathrm{Vc}$ and $\mathrm{Dm}$ at multiple inspired oxygen concentrations (Ceridon et al., 2010). The Roughton and Forster equation is widely used to quantify lung diffusion capacity (DL): where $\theta$ is the binding affinity of $\mathrm{NO}\left(\theta_{\mathrm{NO}}\right)$ or $\mathrm{CO}\left(\theta_{\mathrm{CO}}\right)$ to hgb (Snydet et al., 2008; Ceridon et al., 2010). The equations for $\mathrm{CO}$ and $\mathrm{NO}$ are below;

$$
1 / \mathrm{DLCO}=1 / \mathrm{Dm}_{\mathrm{CO}}+1 /\left(\theta_{\mathrm{CO}} \bullet \mathrm{Vc}\right)
$$

Since NO has a very high affinity for hgb, $\theta_{\mathrm{NO}}$ is almost infinite and thus $1 / \theta_{\mathrm{NO}} \bullet \mathrm{Vc}$ is negligible. This assumption allows that DLNO is equivalent to $\mathrm{Dm}_{\mathrm{NO}}$ (Tamhane et al., 2001; Snydet et al., 2008; Ceridon et al., 2010). Based on the molecular weights and the blood solubility of $\mathrm{NO}$ and $\mathrm{CO}$, a theoretical estimate of Dm can be obtained (Dm CO $=\mathrm{DLNO} / 1.93$ ) (Meyer et al., 1990; Ceridon et al., 2010).

Cardiac output $(\mathrm{Q})$ was measured by using an acetylene $\left(\mathrm{C}_{2} \mathrm{H}_{2}\right)$ inert gas rebreathe technique developed validated in our laboratory using direct FICK. This technique is reliable and sensitive to small changes in work rate (Johnson et al., 2000). This technique was performed during the rebreathe maneuver in which DLCO/DLNO were assessed.

\subsection{Experimental Procedure}

Subjects initially underwent baseline measures of vital capacity (slow-SVC and fast-FVC), residual volume (RV), total lung capacity (TLC), and diffusing capacity of the lungs for nitric oxide (DLNO) and for carbon monoxide (DLCO) while in the upright (sitting) position (Fig. 1). The measurement was repeated 3 times. Subsequently, subjects were placed in the supine position for 30 minutes, and the supine measurements were performed in duplicate at 2 minute (Sup 2) and 25 minute (Sup 25). After completion of the supine measurements, subjects were again brought to the upright (sitting) position for additional resting upright measures. Subsequently, subjects performed cycle ergometry exercise until near peak levels. The cycle ergometer work levels were increased by $10-15 \mathrm{~W}$ every 3 minute with the goal of obtaining 4 work levels per subject (Fig. 1). Exercise measures were assessed once every stage over the last 60 seconds. Lung impedance measures were made continuously throughout the study on a per beat basis.

\subsection{Data Analysis}

All measures were made in triplicate (baseline), duplicate (supine position) and one each per stage (exercise) during the studies. For the triplicate measures, outliers were dropped $(>10 \%$ variation from the other values) while duplicated measures were averaged. For lung impedance measures, the data were extracted via telemetry and averaged over the time the measurements were made for DLCO, Dm and Vc, and EILV (typically $30 \mathrm{sec}$ ). 
Comparisons were made for a given measure under each condition using repeated measures ANOVA with a Tukey post-hoc analyses to determine specific differences between 2 conditions. In addition, correlational analyses (Pearson) were performed between changes in DLCO, Dm, $\mathrm{Vc}$ and measures of $\mathrm{Z}_{\mathrm{T}}$ with positional changes and with increasing exercise intensity. The significance level for the ANOVA, post-hoc analyses and correlation was set at 0.05 . Based on our previous study and known variation in the measurement techniques (Olson et al., 2006), we had estimated that we could detect a 15\% change in measure of DLCO, Dm and Vc with 12 subjects at $80 \%$ power.

\section{RESULTS}

All 12 patients ( 8 males and 4 females, NYHA class I, II and III; $n=3,6$ and 3 respectively) successfully completed the experimental protocol. Body mass index averaged 28.9 \pm 1.4 $\mathrm{kg} / \mathrm{m}^{2}$.and LVEF was $41.4 \pm 4.2 \%$ (Table 1). Figure 2. demonstrates a representative individual impedance displaying the changes across baseline (upright), supine and exercise. In addition, spirometry data during supine position and exercise are illustrated in table 2.

\subsection{Change in impedance over vital capacity}

The difference in lung impedance $\left(\mathrm{Z}_{\mathrm{T}}\right)$ during a slow vital capacity maneuver (RV-TLC) at upright rest is shown in figure 3 . There was a significant increase in $Z_{T}$ from residual volume to total lung capacity $(\mathrm{p}<0.05)$.

\subsection{Influence of body position on $\mathrm{Z}_{\mathrm{T}}$, EILV, $\mathrm{Vc}$ and $\mathrm{Dm} / \mathrm{Vc}$}

Positional change from upright to supine resulted in a significant increase in $\mathrm{Z}_{\mathrm{T}}$ (Fig. 4a, $\mathrm{p}<0.01)$. When compared to the upright position $(77.2 \pm 3.3 \mathrm{ohm}), \mathrm{Z}_{\mathrm{T}}$ was higher at $\operatorname{Sup} 2$ $(81.0 \pm 3.2 \mathrm{ohm})$ and Sup $25(80.4 \pm 3.0 \mathrm{ohm})$. Positional change also altered Vc, Dm/Vc and EILV. As shown in figure $4 \mathrm{~b}, \mathrm{Vc}$ increased with the initiation of the supine position and remained increased over upright after 30 minutes (upright: $49.3 \pm 4.4 \mathrm{ml}$, Sup 2: $78.8 \pm 15.8$ $\mathrm{ml}$, Sup 25: $62.7 \pm 8.2 \mathrm{ml}, \mathrm{p}<0.05)$. Figure $4 \mathrm{c}$ illustrates that $\mathrm{Dm} / \mathrm{Vc}$ decreased initially and increased slightly after 30 minutes (upright: $0.63 \pm 0.06$, Sup 2: 0.35 \pm 0.04 , Sup 25: 0.4 \pm 0.05 , $\mathrm{p}<0.01$ ). In addition, figure $4 \mathrm{~d}$ shows that EILV decreased with the supine position relative to upright (upright: $4258 \pm 238 \mathrm{ml}$, Sup 2: $3617 \pm 210 \mathrm{ml}$, Sup 25: $3488 \pm 177 \mathrm{ml}, \mathrm{p}<0.01$ ).

\subsection{Influence of exercise on $\mathrm{Z}_{\mathrm{T}}$, EILV, Vc and $\mathrm{Dm} / \mathrm{Vc}$}

During exercise, Vc increased (baseline: $54.3 \pm 6.5 \mathrm{ml}$, max: $87.8 \pm 11.6 \mathrm{ml}, \mathrm{p}=0.05$ ) and $\mathrm{Dm} / \mathrm{Vc}$ was decreased relative to rest (baseline: $0.6 \pm 0.06$, max: $0.4 \pm 0.04, \mathrm{p}<0.05$ ). In addition, the average EILV decreased initially and then increased as exercise intensity increased (baseline: $4253 \pm 239 \mathrm{ml}$, max: $4655 \pm 917$, $\mathrm{p} \unlhd 0.01$ ). However, there was no significant change in the average $\mathrm{Z}_{\mathrm{T}}(\mathrm{p}>0.05)$.

\subsection{Relationship of $Z_{T}$, EILV, Vc and $\mathrm{Dm} / \mathrm{Vc}$}

The percent change in $\mathrm{Z}_{\mathrm{T}}$ was poorly associated with the change in $\mathrm{V}_{\mathrm{c}}$ from upright to Sup 2 $(\mathrm{r}=-0.218, \mathrm{p}>0.05)$ and from rest to exercise $(\mathrm{r}=0.120, \mathrm{p}>0.05)$. In addition there was a general lack of relationship between the percent change in $\mathrm{Z}_{\mathrm{T}}$ and change in $\mathrm{Dm} / \mathrm{Vc}$ from upright to $\operatorname{Sup} 2(r=0.142, p>0.05)$ and from rest to exercise $\max (r=-0.300, p>0.05)$. 
However, the change in $\mathrm{Z}_{\mathrm{T}}$ showed a modest relationship with the change in EILV from upright to $\operatorname{Sup} 2(\mathrm{r}=-0.615, \mathrm{p}<0.05)$.

\section{DICUSSION}

\subsection{Summary of findings}

The present study sought to determine the ability of intrathoracic impedance to acutely track measures of extravascular lung water in HF patents. This was pursued due to our interest in the acute effects of positional change and exercise on lung fluid regulation in addition to the known influence of additional physiological variables (blood and air) that influence impedance and also tend to change in the HF population with congestion. Thus beat by beat measures of impedance were obtained during and after the transition from the upright to supine position and with graded increases in exercise intensity. While significant changes were obtained in lung volume (air), pulmonary blood volume and an index of extravascular lung water (ELW) during both interventions, $\mathrm{Z}_{\mathrm{T}}$ appeared relatively insensitive to these more dynamic physiological measures (with the exception of lung volume) and more sensitive to positional changes that likely alters the lead to cam distance or impedance pathways between lead and cam, making intrathoracic $\mathrm{Z}_{\mathrm{T}}$ a poor measure of dynamic changes in thoracic physiology in the HF population.

\subsection{Intrathoracic impedance measurement}

In clinical practice, a number of techniques (i.e., magnetic resonance imaging, computed tomography and positron emission tomography) have been utilized to assess lung fluid accumulation. However, these techniques have some disadvantages which are high cost, exposure to radiation and uncertainty of accuracy (Gupta et al., 2012). On the other hand, intrathoracic impedance is an easily obtained and requires low cost once a device is implanted (Gupta et al., 2012). Furthermore, in the present study, impedance was obtained from indwelling device so that it could continuously tracks intrathoracic fluid. A number of previous studies have reported the strong relationships between intrathoracic impedance and other variables reflecting HF decompensatory changes such as PCWP and acute decompensation of HF (ADHF) re-hospitalization (Yu et al., 2005; Abraham et al., 2009; Small et al., 2009; Maines et al., 2010).

The exact mechanism/s of congestion in HF and the decompensatory changes and time line of these changes remain unclear. However, while gradual changes in ELW can and do occur, it is likely this change is also accompanied by a change in thoracic blood volume as well as a change in lung volume as competition for space occurs in the thorax. Intrathoracic impedance measures lung fluid content based on the fact that electrical current flow decreases as fluid increases because of decreased resistance. Therefore, this technique is only able to measure total lung fluid content without differentiation of extravascular from intravascular fluid (Gupta et al., 2012) and the ability of impedance to represent independent changes in lung water may be confounded by intravascular fluid changes. For example, a rise in pulmonary wedge pressure should cause a rise in pulmonary capillary blood volume which should cause impedance to fall. In addition, the reduced compliance of the lungs (restrictive changes) and increased blood volume could also reduce lung volume although 
some studies suggest air trapping may also occur, and in turn increasing over all lung volume (increasing impedance). Therefore, the causes of changes in impedance could be complicated. Some studies also suggest the development of a reactive form of $\mathrm{PH}$ and a rise in endothelin-1 levels (Giaid et al., 1993; Zamora et al., 1993; Moraes et al., 2000) - with resultant pulmonary vascular constriction, which could further increase impedance. In addition, the pathways where current flow are also complex and slight positional changes may either alter these pathways with varying resistances or alter the pathway length. Thus, in the present study, we initially tried a positional change, given the known condition of orthopnea that occurs in the HF patients (Duguet et al., 2000; Torchio et al., 2006). During recumbency blood volume redistribution from extremities to the lungs and heart, and a rise in central blood volume may increase extravascular lung water; a mild exacerbation of the HF condition. However, with this relatively brief positional change, no specific single physiological variable demonstrated a clear relationship with impedance despite significant changes in EILV, $\mathrm{Vc}$ and $\mathrm{Dm} / \mathrm{Vc}$. These results were not accordant with previous findings suggesting a stronger relationship between impedance and changes in fluid status, (e.g., PCWP and ADHF). However, a concern is that the physiological changes (e.g., ELW) associated with positional change and exercise in this study may have not been great enough to be detected by impedance or our associated techniques. The patients tested, were stable and thus we were clearly not assessing decompensated HF. However, we suggest that the relatively modest changes in Vc (increasing 80\%) and lung volume (increasing 20\%) should be detectable under the right conditions. In addition, in a previous study we demonstrated the ability to detect 20 to $40 \%$ changes in $\mathrm{Dm} / \mathrm{Vc}$ which was equivalent to an estimated 80 100 ml change in lung water (Snyder et al., 2006). Similar changes were observed for $\mathrm{Dm} / \mathrm{Vc}$ in this this study and thus the assumption would be that similar changes occurred in interstitial lung water. In addition, the use of $\mathrm{Dm} / \mathrm{Vc}$ has previously been shown to track heart failure disease severity and to be associated with other common measures such as NYHA and exercise capacity (Puri et al., 1995; Agostoni et al., 2006).

Our goal was to test the capability of the indwelling thoracic impedance to track acute changes in lung fluid during dynamic positional changes and exercise. This type of testing is quite different than the goals or intent of the Medtronic Optivol ${ }^{\mathrm{TM}}$ impedance software. This software obtains averaged daily impedance via measuring impedance several times from 12 $\mathrm{pm}$ to $5 \mathrm{pm}$ each day. Four consecutive impedance measures (one impedance measure/QRS) are averaged. This averaged measure was obtained every 20 minutes, giving a total of 16 averaged measures from 12 to $5 \mathrm{pm}$ to provide daily impedance. A reference impedance is set 34 days post implantation (initially set value is normally $60 \mathrm{ohms}$ ). The device tracks the changes in daily impedance, and if daily averaged impedance falls below the reference value, the observation is triggered. Therefore, previous studies tended to examine relationship over a longer time interval (Yu et al., 2005; Maines et al., 2010; Conraads et al., 2011). Indeed, Tang and Tong (2009) determined that intrathoracic impedance measurements are more accurate for detecting trends over time. In addition, a study by Conraads et al. (2011) illustrated that intrathoracic impedance showed low sensitivity in early stages post device implantation, but improved within the first 6 months. Thus, we suggest that intrathoracic impedance measurement is more likely to provide an advantage to 
predict fluid status over extended time periods (from days to months) and best if controlled for body position.

Impedance is also highly influenced by alterations in intrathoracic air (Kramer and Maisel, 2011). We confirmed that impedance was significantly influenced by lung volume over vital capacity during upright resting. However, we observed that impedance increased during the supine position when end inspiratory lung volume decreased. Therefore it is likely that mechanical or/and physiological confounding factors override the effect of intrathoracic air on impedance. The most likely hypothesis is related to the mechanical influence during positional change from upright to supine. Implanted impedance device measures electrical impulse vector from the pulse generator (left pectoral region) to the lead (located in right ventricle of the heart). It is likely that positional change from upright to supine resulted in the widening between the pulse generator and the lead so that it possibly increased impedance. Interestingly, impedance also did not change directionally during exercise while end inspiratory lung volume increased (theoretically increasing $\mathrm{Z}_{\mathrm{T}}$ ) and lung fluid and capillary volume also increased (theoretically decreasing $\mathrm{Z}_{\mathrm{T}}$ ), thus potentially negating directional change.

The limitations to utilize implanted impedance, e.g., right ventricle failure or unilateral right lung edema due to the location of the implanted device, have been reported by previous studies (Kramer and Maisel, 2011; Horman and Abboud, 2013). However, it may still provide important clinical information examining trends over long periods of time, especially if assessed quietly at rest in a given position.

\subsection{Limitations}

This was an experimental study to determine if indwelling thoracic measures of impedance can track acute changes in extravascular fluid (water) and/or pulmonary vascular fluid (blood) during positional change and exercise. There are limitations. In the present study, Vc increased and $\mathrm{Dm} / \mathrm{Vc}$ and EILV decreased during the supine position so that a decrease in impedance was expected, however, we observed an overall increased impedance. Most likely this change in impedance was caused by an alteration in the impedance pathway and/or the distance between the device box and the lead due to the change in anatomical position which overwhelmed any smaller change in $\mathrm{Z}_{\mathrm{T}}$ related to blood, air or water.

\subsection{Conclusion}

Intrathoracic impedance from indwelling devices in $\mathrm{HF}$ is highly sensitive to positional change apparently independent of dynamic changes in lung water, lung blood volume or air volume, likely due to a change in impedance pathways and/or due to changes in the distance from the pulse generator to the lead. In addition, impedance is sensitive to changes in lung volume at rest, in the upright position during vital capacity maneuvers, but insensitive to expected changes in extravascular lung water, pulmonary capillary blood volume and lung volume during sustained position change or exercise. Despite, the inability of impedance to singularly track lung fluid under dynamic conditions, it likely it still yields important clinical information since it may reflect more general changes in thoracic fluid and air volumes, 
under less dynamic conditions and more dramatic changes in thoracic fluid, such as decompensation.

\section{Acknowledgments}

The author would like to thank the subjects for their participation in the study and Kathy O'Malley for her help with subject recruitment and data collection

\section{Funding source}

NIH grant HL71478 and Medtronics Company

\section{References}

Abraham WT, Compton S, Haas G, Foreman B, Canby RC, Fishel R, McRae S, Toledo GB, Sarkar S. FAST investigators. Superior Performance of Intrathoracic Impedance-Derived fluid Index versus Daily Weight monitoring in Heart Failure Patients: Results of the Fluid Accumulation Status Trial (FAST). J Card Fail. 2009; 15:813-813.

Agostoni P, Bussotti M, Cattadori G, Margutti E, Contini M, Muratori M, Marenzi G, Fiorentini C. Gas diffusion and alveolar-capillary unit in chronic heart failure. Eur Heart J. 2006; 27:2538-2543. [PubMed: 17028107]

Andriulli J. Device monitoring of intrathoracic impedance: Clinical observations from a patient registry. Am J Cardiol. 2007; 99:23g-28g.

Becher J, Kaufmann SG, Paule S, Fahn B, Skerl O, Bauer WR, Ertl G, Maier SKG. Device-based impedance measurement is a useful and accurate tool for direct assessment of intrathoracic fluid accumulation in heart failure. Europace. 2010; 12:731-740. [PubMed: 20056595]

Ceridon ML, Beck KC, Olson TP, Bilezikian JA, Johnson BD. Calculating alveolar capillary conductance and pulmonary capillary blood volume: comparing the multiple- and single-inspired oxygen tension methods. J Appl Physiol. 2010; 109:643-653. [PubMed: 20538842]

Ceridon M, Wanner A, Johnson BD. Does the bronchial circulation contribute to congestion in heart failure? Med Hypotheses. 2009; 73:414-419. [PubMed: 19464810]

Cleland JGF, Swedberg K, Follath F, Komajda M, Cohen-Solal A, Aguilar JC, Dietz R, Gavazzi A, Hobbs R, Korewicki J, Madeira HC, Moiseyev VS, Preda I, van Gilst WH, Widimsky J, Freemantle $\mathrm{N}$, Eastaugh J, Mason J. The EuroHeart Failure survey programme - a survey on the quality of care among patients with heart failure in Europe - Part 1: patient characteristics and diagnosis. Eur Heart J. 2003; 24:442-463. [PubMed: 12633546]

Conraads VM, Tavazzi L, Santini M, Oliva F, Gerritse B, Yu CM, Cowie MR. Sensitivity and positive predictive value of implantable intrathoracic impedance monitoring as a predictor of heart failure hospitalizations: the SENSE-HF trial. Eur Heart J. 2011; 32:2266-2273. [PubMed: 21362703]

Duguet A, Tantucci C, Lozinguez O, Isnard R, Thomas D, Zelter M, Derenne JP, Milic-Emili J, Similowski T. Expiratory flow limitation as a determinant of orthopnea in acute left heart failure. $\mathrm{J}$ Am Coll Cardiol. 2000; 35:690-700. [PubMed: 10716472]

Giaid A, Yanagisawa M, Langleben D, Michel RP, Levy R, Shennib H, et al. Expression of Endothelin-1 in the Lungs of Patients with Pulmonary-Hypertension. New Engl J Med. 1993; 328:1732-1739. [PubMed: 8497283]

Gupta RKNRD, Newbould RD, Matthews PM. Methods of measuring lung water. Journal of intensive care society. 2012; 13:209-215.

Horman KA, Abboud S. Parametric EIT vs. intra-thoracic impedance for monitoring pulmonary edema using a two dimensional theoretical model of the thorax. International Journal of Medical Engineering and Informatics. 2013; 5:117-125.

Johnson BD, Beck KC, Proctor DN, Miller J, Dietz NM, Joyner MJ. Cardiac output during exercise by the open circuit acetylene washin method: comparison with direct Fick. J Appl Physiol. 2000; 88:1650-1658. [PubMed: 10797126] 
Kramer DB, Maisel WH. An Unusual Cause of Abnormal Intrathoracic Impedance in a Patient with Arrhythmogenic Right Ventricular Cardiomyopathy. Pace. 2011; 34:E60-E63. [PubMed: 20456645]

Lepage S. Acute decompensated heart failure. Can J Cardiol. 2008; 24:6B-8B.

Lewin J, Ledwidge M, O’Loughlin C, McNally C, McDonald K. Clinical deterioration in established heart failure: What is the value of BNP and weight gain in aiding diagnosis? Eur J Heart Fail. 2005; 7:953-957. [PubMed: 16227134]

Mahdyoon H, Klein R, Eyler W, Lakier JB, Chakko SC, Gheorghiade M. Radiographic pulmonary congestion in end-stage congestive heart failure. Am J Cardiol. 1989; 63:625-627. [PubMed: 2919567]

Maines M, Catanzariti D, Cirrincione C, Valsecchi S, Comisso J, Vergara G. Intrathoracic impedance and pulmonary wedge pressure for the detection of heart failure deterioration. Europace. 2010; 12:680-685. [PubMed: 20047927]

Meyer M, Schuster KD, Schulz H, Mohr M, Piiper J. Pulmonary Diffusing Capacities for Nitric-Oxide and Carbon-Monoxide Determined by Rebreathing in Dogs. J Appl Physiol. 1990; 68:2344-2357. [PubMed: 2384415]

Moraes DL, Colucci WS, Givertz MM. Secondary pulmonary hypertension in chronic heart failure The role of the endothelium in pathophysiology and management. Circulation. 2000; 102:17181723. [PubMed: 11015353]

Olson TP, Frantz RP, Snyder EM, O'Malley KA, Beck KC, Johnson BD. Effects of acute changes in pulmonary wedge pressure on periodic breathing at rest in heart failure patients. Am Heart J. 2007:153. [PubMed: 17239670]

Olson LJ, Snyder EM, Beck KC, Johnson BD. Reduced rate of alveolar-capillary recruitment and fall of pulmonary diffusing capacity during exercise in patients with heart failure. J Card Fail. 2006; 12:299-306. [PubMed: 16679264]

Puri S, Baker BL, Dutka DP, Oakley CM, Hughes JMB, Cleland JGF. Reduced Alveolar-Capillary Membrane Diffusing-Capacity in Chronic Heart-Failure - Its pathophysiological Relevance and Relationship to Exercise Performance. Circulation. 1995; 91:2769-2774. [PubMed: 7758183]

Roger VL, Go AS, Lloyd-Jones DM, Benjamin EJ, Berry JD, Borden WB, Bravata DM, Dai S, Ford ES, Fox CS, Fullerton HJ, Gillespie C, Hailpern SM, Heit JA, Howard VJ, Kissela BM, Kittner SJ, Lackland DT, Lichtman JH, Lisabeth LD, Makuc DM, Marcus GM, Marelli A, Matchar DB, Moy CS, Mozaffarian D, Mussolino ME, Nichol G, Paynter NP, Soliman EZ, Sorlie PD, Sotoodehnia N, Turan TN, Virani SS, Wong ND, Woo D, Turner MB. Amer Heart Assoc Stat Comm, Stroke Stat Subcomm. Heart Disease and Stroke Statistics-2012 Update A Report From the American Heart Association. Circulation. 2012; 125:E2-E220. [PubMed: 22179539]

Ross JS, Chen J, Lin Z, Bueno H, Curtis JP, Drye EE, Keenan PS, Normand SLT, Schreiner GC, Spertus JA, Vidan M, Wang Y, Wang YF, Krumholz HM. Recent National Trends in Heart Failure Readmission Rates. J Am Coll Cardiol. 2009; 53:A387-A387.

Snyder EM, Beck KC, Hulsebus ML, Breen JF, Hoffman EA, Johnson BD. Short-term hypoxic exposure at rest and during exercise reduces lung water in healthy humans. J Appl Physiol. 2006; 101:1623-1632. [PubMed: 16902060]

Snyder EM, Olson TP, Johnson BD, Frantz RP. Influence of sildenafil on lung diffusion during exposure to acute hypoxia at rest and during exercise in healthy humans. Eur J Appl Physiol. 2008; 103:421-430. [PubMed: 18369657]

Small RS, Wickemeyer W, Germany R, Hoppe B, Andrulli J, Brady PA, Labeau M, Koehler J, Sarkar S, Hettrick DA, Tang WHW. Changes in Intrathoracic Impedance are Associated With Subsequent Risk of Hospitalizations for Acute Decompensated Heart Failure: Clinical Utility of Implanted Device Monitoring Without a Patient Alert. J Card Fail. 2009; 15:475-481. [PubMed: 19643357]

Tamhane RM, Johnson RL, Hsia CCW. Pulmonary membrane diffusing capacity and capillary blood volume measured during exercise from nitric oxide uptake. Chest. 2001; 120:1850-1856. [PubMed: 11742912]

Tang WHW, Tong W. Measuring impedance in congestive heart failure: Current options and clinical applications. Am Heart J. 2009; 157:402-411. [PubMed: 19249408] 
Torchio R, Gulotta C, Greco-Lucchina P, Perboni A, Avonto L, Ghezzo H, Milic-Emili J. Orthopnea and tidal expiratory flow limitation in chronic heart failure. Chest. 2006; 130:472-479. [PubMed: 16899847]

Vollmann D, Nagele H, Schauerte P, Wiegand U, Butter C, Zanotto G, Quesada A, Guthmann A, Hill MRS, Lamp B. Clinical utility of intrathoracic impedance monitoring to alert patients with an implanted device of deteriorating chronic heart failure. Eur Heart J. 2007; 28:1835-1840. [PubMed: 17309902]

Wang L. Fundamentals of intrathoracic impedance monitoring in heart failure. Am J Cardiol. 2007; 99:3G-10G.

Ypenburg C, Bax JJ, van der Wall EE, Schalij MJ, van Erven L. Intrathoracic impedance monitoring to predict decompensated heart failure. Am J Cardiol. 2007; 99:554-557. [PubMed: 17293202]

Yu CM, Wang L, Chau E, Chan RHW, Kong SL, Tang MO, Christensen J, Stadler RW, Lau CP. Intrathoracic impedance monitoring in patients with heart failure - Correlation with fluid status and feasibility of early warning preceding hospitalization. Circulation. 2005; 112:841-848. [PubMed: 16061743]

Zamora MA, Dempsey EC, Walchak SJ, Stelzner TJ. Bq123, an Et(a) Receptor Antagonist, Inhibits Endothelin-1-Mediated Proliferation of Human Pulmonary-Artery Smooth-Muscle Cells. Am J Resp Cell Mol. 1993; 9:429-433. 


\section{Highlights}

- Intrathoracic impedance increased with lung volume during slow vital capacity maneuvers.

- Positional changes (upright to supine) resulted in increased impedance, while pulmonary blood volume increased, and an index of extravascular lung water and lung volume decreased.

- During exercise, lung volume and pulmonary blood volume increased, and an index of extravascular lung water decreased. However, impedance was not altered significantly. 


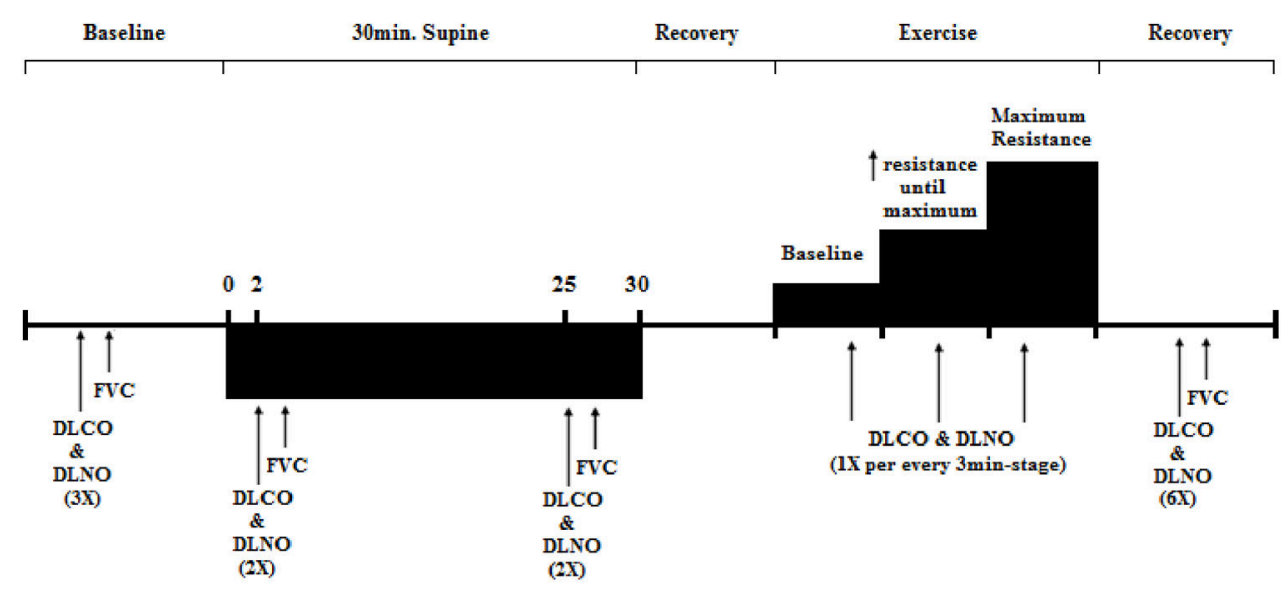

Figure 1.

Experimental Protocol and timeline that consist of baseline, supine position, exercise and recovery measurements. (1X: repeat 1 time, $2 \mathrm{X}$ : repeat 2 times, $3 \mathrm{X}$ : repeat 3 times, $6 \mathrm{X}$ : repeat 6 times). 


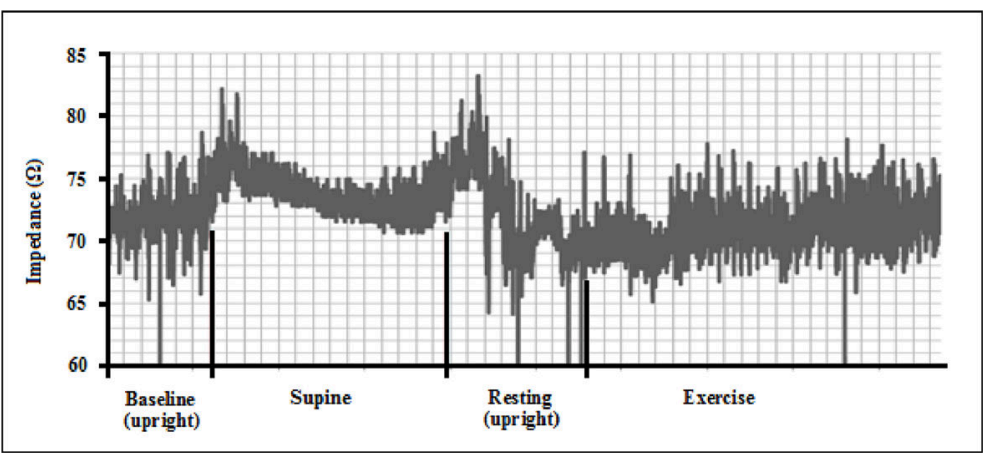

Figure 2.

A representative individual impedance data displaying the changes across upright and resting, supine and exercise. 


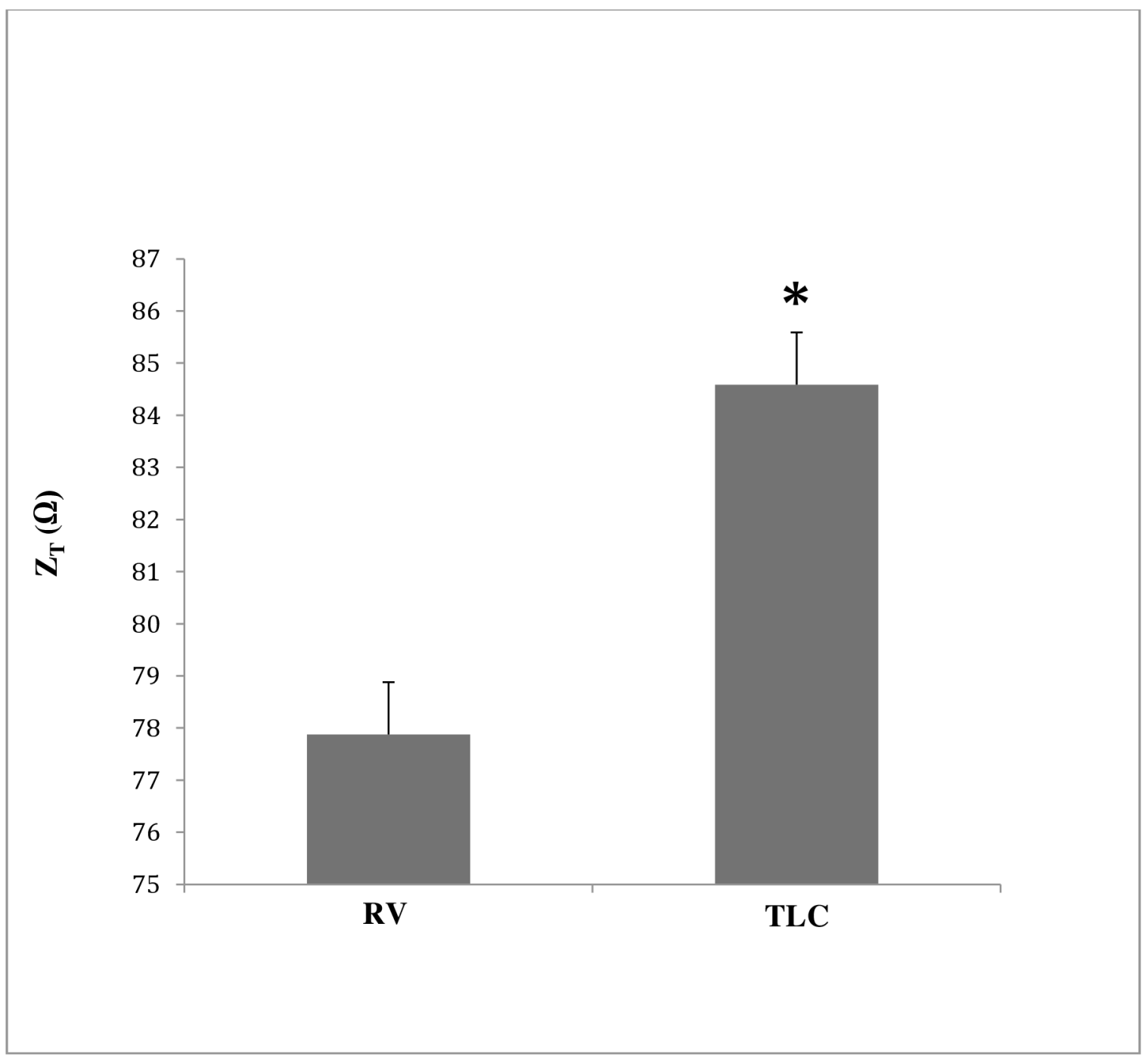

Figure 3.

Change in $\mathrm{Optivol}^{\mathrm{TM}}$ impedance over Vital capacity range at upright position during resting. $*$ denotes significance level $(\mathrm{p}<0.05)$. 
a)

c)

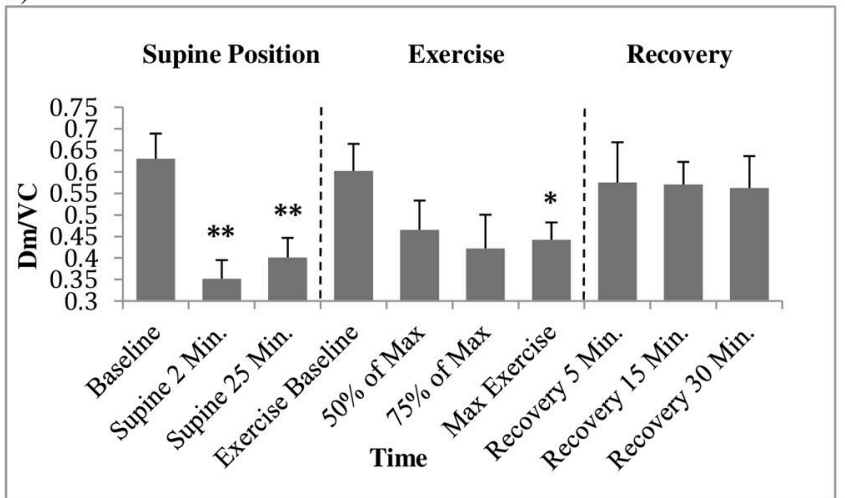

Figure 4. b)

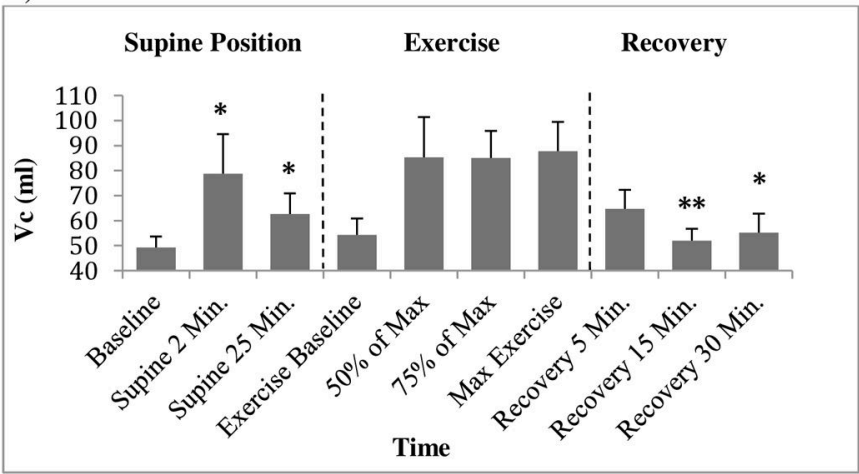

d)

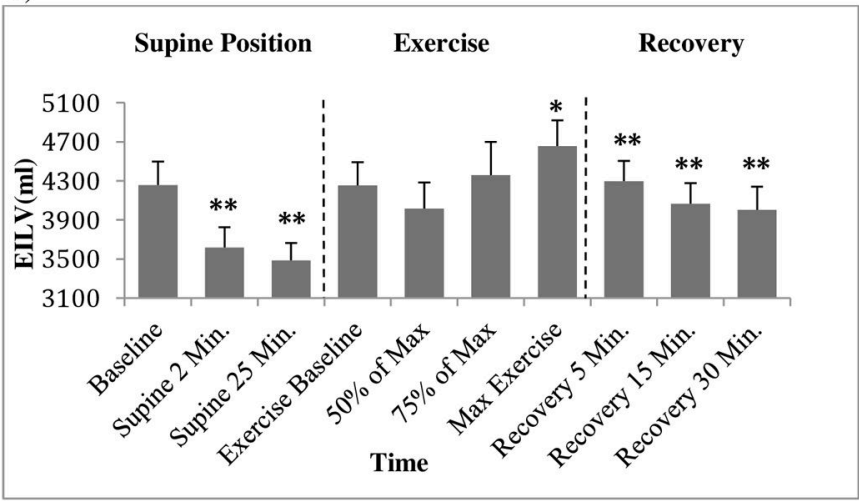

Change in 3a) Optivol $^{\mathrm{TM}}$ impedance $\left.\left(\mathrm{Z}_{\mathrm{T}}\right), 3 \mathrm{~b}\right)$ pulmonary-capillary blood volume $\left.(\mathrm{Vc}), 3 \mathrm{c}\right)$ interstitial fluid index $(\mathrm{Dm} / \mathrm{Vc})$ and $3 \mathrm{~d})$ End Expiratory Lung Volume (EILV) during supine position, exercise and recovery. $*(\mathrm{p}<0.05)$ and $* *(\mathrm{p}<0.01)$ in supine position denote significant difference when comparing to baseline. $*$ and $* *$ in exercise denote significant difference when comparing to pre-exercise. $*$ and $* *$ in recovery denote significant difference when comparing to max-exercise. 


\section{Table 1}

Participant characteristics

\begin{tabular}{ccc}
\hline Characteristics & Mean \pm SEM & Range \\
\hline Demographic (n=12) & & \\
Gender (M/F) & $(8 / 4)$ & \\
Age (yr) & $63 \pm 2$ & $49-74$ \\
Height (cm) & $171 \pm 3$ & $154-188$ \\
Weight (Kg) & $84 \pm 5$ & $61-119$ \\
Body mass index (kg/m $\left.{ }^{2}\right)$ & $28.9 \pm 1.4$ & $21.6-38.5$ \\
Left ventricular ejection fraction (\%) & $41.4 \pm 4.2$ & $25-62$ \\
B-Type Natriuretic Peptide (pg/ml) & $439 \pm 198$ & $41-1803$ \\
NT-PRO Brain natriuretic peptide (pg/ml) & $816 \pm 348$ & $73-1015$ \\
Etiology (ischemic / dilated / idiopathic) & $6 / 5 / 1$ & \\
Medtronic CRT-D (7289 / 7299 / 7303 / C154DWK) & $3 / 7 / 1 / 1$ & \\
New York Heart Association Class (I / II / III) & $3 / 6 / 3$ & \\
Medications (\% on medication) & & \\
Angiotensin converting enzyme inhibitors & 66.7 & \\
All receptor blockers & 25.0 & \\
$\beta$-Blockers & 100 & \\
Digitalis & 41.7 & \\
Aspirin & 50.0 & \\
\hline
\end{tabular}

Respir Physiol Neurobiol. Author manuscript; available in PMC 2015 October 01. 


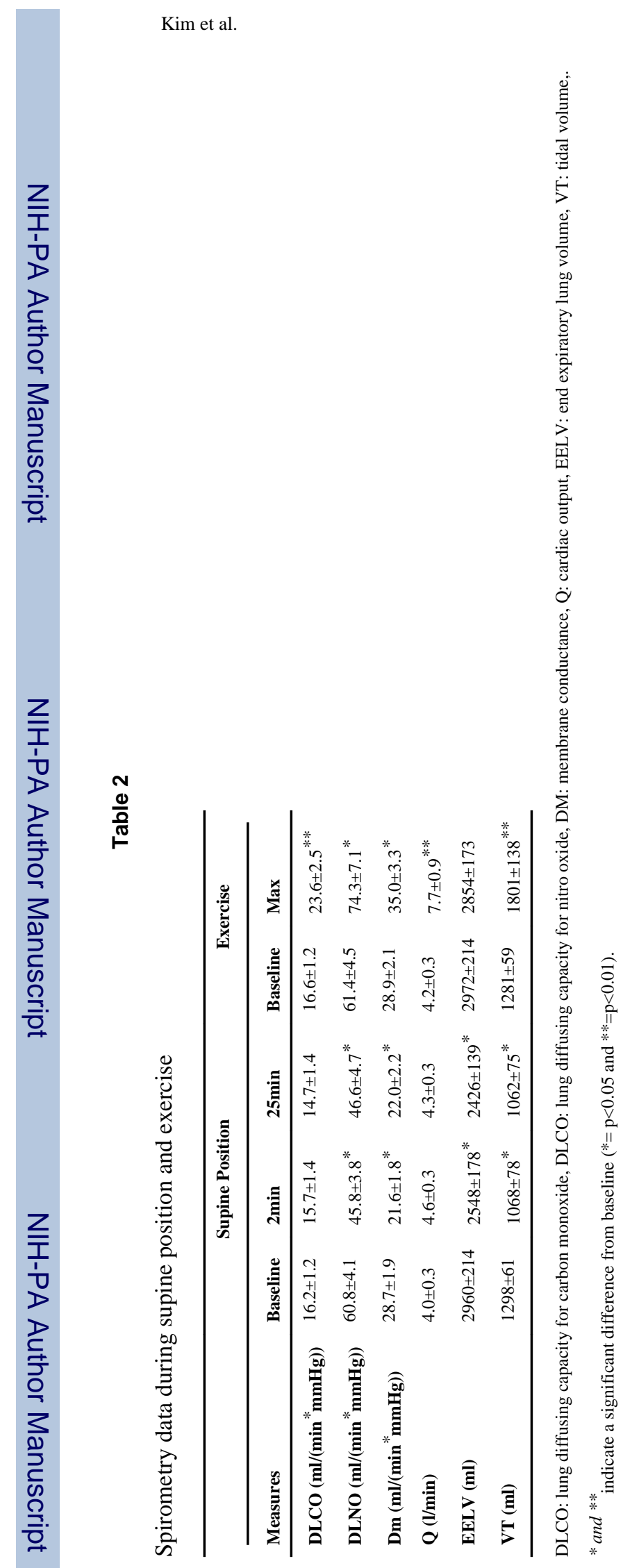

Respir Physiol Neurobiol. Author manuscript; available in PMC 2015 October 01. 